\title{
INTRACELLULAR AND EXTRACELLULAR CRYSTALLINE INCLUSIONS IN A CASE OF MYELOMA: A CASE REPORT
}

G. N. Srinivas, Anitha B. Chalageri, Anjana Gupta, Manjula. V.

1. Chief Pathologist, Department of Pathology SRL Diagnostics - KCDC Mysore.

2. Consultant Pathologist, Department of Pathology SRL Diagnostics - KCDC Mysore.

3. Consultant Pathologist, Department of Pathology SRL Diagnostics - KCDC Mysore.

4. Consultant Pathologist, Department of Pathology SRL Diagnostics - KCDC Mysore.

\section{CORRESPONDING AUTHOR}

Dr. Anitha B. Chalageri, MD

Consultant Pathologist

SRL Diagnostics - KCDC

125 /2a, Irwin Road

Mysore- 570001, Karnataka.

E-mail: anitha.chalageri@gmail.com.

Ph: 00919480168021.

ABSTRACT: The presence of crystalline inclusions in plasma cell myeloma is a rare phenomenon and cases have been reported with rod, needle, and rectangular shaped crystals in the bone marrow. Here, we present a case of plasma cell myeloma with intracellular crystalline eosinophilic inclusions and extracellular crystal depositions in the bone marrow. Since crystal depositions can be seen in many other clinical conditions, this case invites consideration of plasma cell myeloma in the differential diagnosis of patients with crystalline deposition in the bone marrow and in sites/organs other than the bone marrow.

KEYWORDS: Bone marrow, crystals, Myeloma, plasma cell.

INTRODUCTION: Plasma cell dyscrasias are a heterogeneous group of disorders characterised by the expansion of a single clone of immunoglobulin secreting, terminally differentiated, endstage B cells.[1] Many of their clinical and morphological features are the result of the production and accumulation of excessive amounts of monoclonal immunoglobulin.[2,3] Plasma cell myeloma stems from malignant transformation of plasma cells with frequent overproduction of immunoglobulins. Its clinical presentation with intracellular and extracellular crystalline inclusions is a rare but recognized phenomenon. ${ }^{[4-6]}$ Crystalline inclusions with rod, needle, and rectangular shapes have been associated with free kappa or with IgA, IgD, IgG, and kappa light chain gammopathies.[7-9] It has been determined that crystalline structures are of immunoglobulin origin and are found not only in plasma cells but also in other hematopoietic cells. ${ }^{[8]}$ Here, we present a case of plasma cell myeloma with intracytoplasmic crystalline inclusions and extracellular crystal deposition.

CASE PRESENTATION: The patient is a 53 year-old male who was referred to a hematologist for work-up of anemia and leukopenia. He has had a gradual and persistent decrease in his hemoglobin levels during the past few years associated with mild leukopenia. ESR was $150 \mathrm{~mm} / \mathrm{hr}$. The protein level in a 24-hour urine sample was $1860 \mathrm{mg}$. Bence Jones protein was not detected in urine. Serum protein electrophoresis revealed a hypergammaglobulinemia pattern. Serial radiographs of the calvarium, cervical, thoracic, lumbar spine, as well as bilateral humeri and femora did not show lytic lesions. 
Both, the bone marrow biopsy and aspirate had normocellular to hypercellular bone marrow with trilineage hematopoiesis, slightly decreased myeloid and erythroid series and an increased population of plasma cells. Megakaryocytes were present in adequate number and had an unremarkable morphology. The plasma cell population included a subset with round conspicuous nucleoli and intracytoplasmic, single or multiple eosinophilic crystalline rod shaped, rhomboid, needle shaped and rectangular structures (Fig 1). Scattered free extracellular crystals were also noted (Fig 2). There was an associated giant cell reaction. A Congo red stain to evaluate for possible amyloid deposition was negative.

DISCUSSION: Plasma cell crystalline inclusions with rod, rectangular, and needle-like shapes have been described in cases of multiple myeloma and they are believed to be due to accumulation of cytoplasmic immunoglobulins secondary to a block in the protein synthetic pathway. ${ }^{[4-7]}$ It is of note that it has been postulated that the presence of crystalline inclusions may indicate a nonprogressive clinical course of the disease.[10]

Rectangular, rod-like and rhomboid-like crystals in the joints could be seen in cases of calcium pyrophosphate dihydrate (CPPD) crystal deposition disease or pseudogout.[11] Colourless, refractile oxalate crystal deposition in the bone marrow interstitium occurs in oxalosis.[12] Macrophages laden with cholesterol and cystine crystals may be identified in hyperlipidaemic states and in cystinosis respectively. [12] All of these appear different to the eosinophilic crystals described in the current case.

Renal parenchyma damage in patients with plasma cell myeloma is frequent and well characterized and can involve crystal depositions.[13]The skin and subcutaneous tissue could also be a site of crystalline depositions in patients with plasma cell myeloma. [14]

The differential diagnosis in cases of plasma cell intracytoplasmic crystalline inclusions should also include reactive processes, since it has been shown to occur in cases of helicobacter associated gastritis.[15] In the case presented here, a reactive process is ruled out due to the monotypic nature of the plasma cell population.

Finally, crystalline inclusions similar to those seen in plasma cell myeloma have been described in cases of granulocytic sarcoma.[16]

The literature suggests that plasma cell myeloma and crystal deposition can occur in different sites such as joints, kidneys, skin and cornea in addition to bone marrow. The chief importance of these crystals is their morphological pointer towards the diagnosis of a clonal plasma cell proliferation.

CONCLUSIONS: The case presented here illustrates an unusual finding in a patient with plasma cell myeloma. This case and the review of similar cases presented in the literature suggest that crystals in the bone marrow and extramedullary sites such as articular spaces or renal parenchyma should raise suspicion of a plasma cell neoplasm, yet other differential diagnoses such as granulocytic sarcoma or reactive processes should also be considered.

\section{REFERENCES:}

1. Grogan TM, Van Camp B, Kyle RA, et al. Plasma cell neoplasms. In: Jaffe ES, Harris NL, Stein $\mathrm{H}$, et al, eds. World Health Organization classification oftumours.Pathology and genetics of haematopoietic and lymphoid tissues. Lyon: IARC Press, 2001:142-56.

2. Russell W. An address on a characteristic organism of cancer. BMJ 1890;2:1356-60. 
3. Bessis MC. Ultrastructure of lymphoid and plasma cells in relation to globulin and antibody formation. Lab Invest 1961;10:1040-67.

4. Patriarca C, Giunta P, Di Pasquale M, Comande M: Images in pathology. Crystalline inclusions in plasma cell myeloma. Int J Surg Pathol 2007,15:301.

5. Gruszecki AC, Reddy VV: Plasma cell crystalline inclusions. Arch Pathol Lab Med 2002, 126:755.

6. Brodie C, Agrawal S, Rahemtulla A, O'Shea D, Lampert I, Naresh KN: Multiple myeloma with bone marrow extracellular crystal deposition. J Clin Pathol 2007, 60:1064-1065.

7. Raman SB, Van Slyck EJ: Nature of intracytoplasmic crystalline inclusions in myeloma cells (morphologic, cytochemical, ultrastructural, and immunofluorescent studies). Am J Clin Pathol 1983, 80:224-228.

8. Gabriel L, Escribano L, Perales J, Bellas C, Odriozola J, Navarro JL: Multiple myeloma with crystalline inclusions in most hemopoietic cells. Am J Hematol 1985, 18:405-411.

9. Jennette JC, Wilkman AS, Benson JD: IgD myeloma with intracytoplasmic crystalline inclusions. Am J Clin Pathol 1981, 75:231-235.

10. Levine SB, Bernstein LD: Crystalline inclusions in multiple myeloma. JAMA 1985, 254:1985.

11. Rodriguez-Paez AC, Seetharaman M, Brent LH: Cryoglobulin crystal arthropathy in a patient with multiple myeloma. J Clin Rheumatol 2009, 15:238-240.

12. Bain BJ, Clark DM, Lampert IA, et al. Miscellaneous disorders. In: Bone marrow pathology, 3rd edn. Oxford: Blackwell Science, 2001:391-429.

13. Kapur U, Barton K, Fresco R, Leehey DJ, Picken MM: Expanding the pathologic spectrum of immunoglobulin light chain proximal tubulopathy. Arch Pathol Lab Med 2007, 131:1368-1372.

14. Pock L, Stuchlik D, Hercogova J: Crystal storing histiocytosis of the skin associated with multiple myeloma. Int J Dermatol 2006, 45:1408-1411.

15. Stewart CJ, Spagnolo DV: Crystalline plasma cell inclusions in helicobacter-associated gastritis. J Clin Pathol 2006, 59:851-854

16. Strauchen JA, Gordon RE: Crystalline inclusions in granulocytic sarcoma. Arch Pathol Lab Med 2002, 126:85-86.

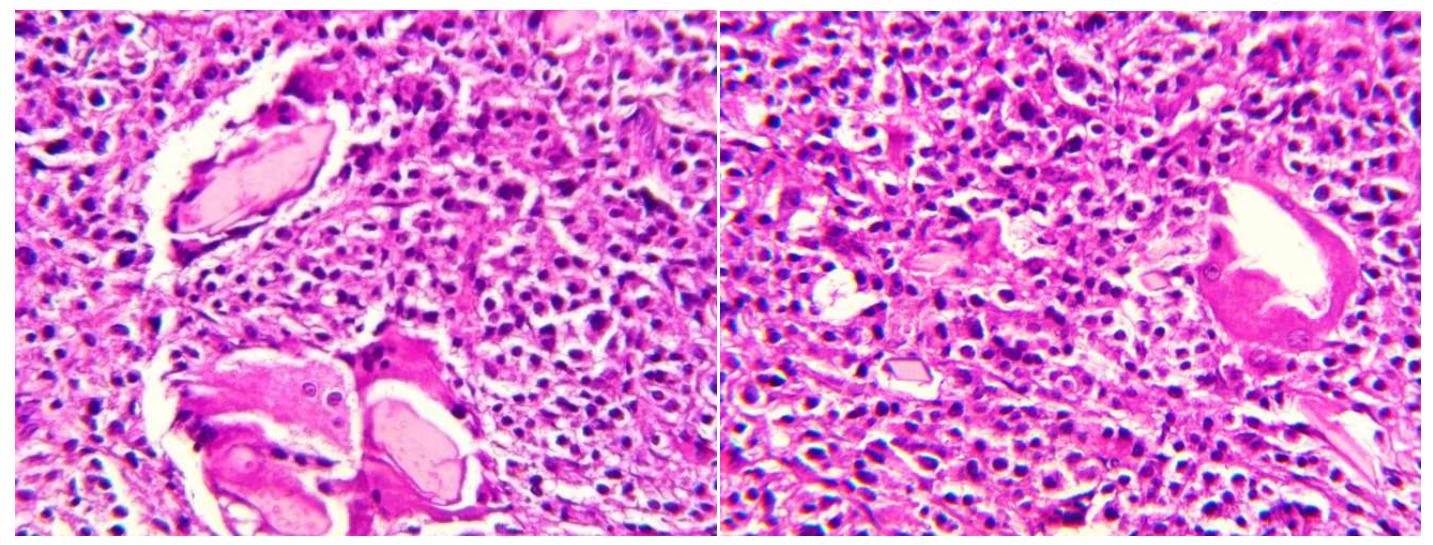

Fig 1 : " Sheets of abnormal plasma cells

Fig 2 : Scattered free extracellular crystals. 10x. H \& E and crystalline inclusions. 10x. H \& E 